\title{
Mechanism of Polycomb Group Gene Silencing
}

\author{
Y. ZHANG, ${ }^{*}$ R. CAO, ${ }^{*}$ L. WANG, ${ }^{\dagger}$ AND R.S. JONES ${ }^{\dagger}$ \\ *Department of Biochemistry and Biophysics, Lineberger Comprehensive Cancer Center, \\ University of North Carolina at Chapel Hill, Chapel Hill, North Carolina 27599-7295; \\ ${ }^{\dagger}$ Department of Biological Sciences, Southern Methodist University, Dallas, Texas 75275
}

The Drosophila trithorax-group (trxG) and Polycombgroup $(\mathrm{PcG})$ proteins function in an antagonistic manner to maintain the transcriptionally active and silence states of target genes, respectively. Although they regulate numerous genes, mutant alleles of most trxG and $\mathrm{PcG}$ genes were first identified on the basis of homeotic phenotypes resulting from misexpression of Hox genes of the Antennapedia and bithorax gene complexes. Drosophila Hox genes, which encode transcription factors that regulate numerous downstream genes, must be continuously expressed in appropriate patterns throughout embryonic and larval development in order to assign segmental identities to cells along the anterior-posterior body axis. The expression patterns of the Hox genes are initially established in early embryos by activators and repressors encoded by gap and pair rule genes, but soon after Hox gene expression is initiated, these activators and repressors decay. It is during this window of time that trxG and PcG proteins somehow recognize the transcriptionally active or repressed states of Hox genes and become responsible for maintaining their expression states in cell lineages throughout embryonic and larval development. Thus, trxG and PcG proteins serve as molecular memory systems central to the process of cellular determination (Francis and Kingston 2001; Simon and Tamkun 2002).

Here we discuss our recent progress in understanding the mechanisms of PcG silencing, but, because PcG proteins function antagonistically to the trxG, we will first briefly describe the trxG and the mechanisms by which they help maintain transcriptional activity. The trxG comprises approximately 20 genes. Several encode components of the 2-MD Brahma (BRM) complex, which is a member of the SWI/SNF family of nucleosome remodeling complexes (Papoulas et al. 1998; Kal et al. 2000), and others encode proteins that are members of the SWI2/SNF2 family of ATPases, but are physically independent of the BRM complex (Daubresse et al. 1999; Ruhf et al. 2001). Two members of the trxG, Trithorax (Trx) and Abnormal small or homeotic discs-1 (ASH-1), contain SET domains [Su(var)3-9, Enhancer of zeste, Trx], conserved domains present in numerous chromatin proteins that possess histone lysine methyltransferase (HMTase) activity (Jenuwein et al. 1998; Rea et al. 2000). Both Trx and ASH-1 methylate histone $\mathrm{H} 3$ at lysine 4 (H3-K4) (Beisel et al. 2002; Byrd and Shearn 2003; Smith et al. 2004), a modification generally associated with gene activation (Bernstein et al. 2002). Trx coexists in the 1-MD TAC1 complex with dCBP, a histone acetyltransferase, and dSbf1 (Petruk et al. 2001).

Originally identified as regulators of Drosophila Hox genes, PcG homologs have since been identified across a wide phylogenetic spectrum, including Caenorhabditis elegans, Arabidopsis thalania, and mammals. A list of Drosophila PcG proteins and their mammalian homologs are provided in Table 1. Thus, PcG proteins appear to be an evolutionarily conserved gene-silencing system that has been adapted for the regulation of different genes and developmental purposes. The Drosophila $\mathrm{PcG}$ comprises approximately 15 genes, many of which encode components of multiprotein complexes. The Polycomb repressive complex 1 (PRC1) contains the PcG proteins Polycomb (Pc),

Table 1. A List of Known PcG Proteins in Drosophila and Mammalians

\begin{tabular}{|c|c|c|}
\hline $\begin{array}{l}\text { Drosophila } \\
\text { proteins }\end{array}$ & $\begin{array}{l}\text { Human } \\
\text { proteins }\end{array}$ & $\begin{array}{l}\text { Mouse } \\
\text { proteins }\end{array}$ \\
\hline \multicolumn{3}{|c|}{ Sequence-specific DNA-binding proteins } \\
\hline Pho & YY1 & Yy1 \\
\hline Phol & YY1 & Yy1 \\
\hline \multicolumn{3}{|c|}{ Esc-E(z) complex } \\
\hline Esc & EED & Eed \\
\hline \multirow[t]{2}{*}{$\mathrm{E}(\mathrm{z})$} & EZH1 & Ezh1/Enx2 \\
\hline & EZH2 & Ezh2/Enx1 \\
\hline $\mathrm{Su}(\mathrm{z}) 12$ & SUZ12 & Suz12 \\
\hline \multicolumn{3}{|c|}{ PRC1 complex } \\
\hline \multirow[t]{3}{*}{$\mathrm{Pc}$} & $\mathrm{HPC} 1 / \mathrm{CBX} 2$ & $\mathrm{M} 33 / \mathrm{Cbx} 2$ \\
\hline & $\mathrm{HPC} 2 / \mathrm{CBX} 4$ & $\mathrm{Mpc} 2 / \mathrm{Cbx} 4$ \\
\hline & НPC3/CBX8 & \\
\hline \multirow[t]{3}{*}{$\mathrm{Ph}$} & HPH1/EDR1 & Mph1/Rae28/Rae28 \\
\hline & HPH2/EDR2 & $\mathrm{Mph} 2 / \mathrm{Edr} 2$ \\
\hline & HPH3/EDR3 & \\
\hline \multirow{2}{*}{ dRing/Sce } & RING1/RNF1/RING1A & Ring1/Ring1a \\
\hline & RING1B/RNF2 & Ring1b/Rnf2 \\
\hline \multirow[t]{3}{*}{ Psc } & BMI1 & Bmil \\
\hline & ZFP144/RNF110 & Mel18/Zfp144/Rnf110 \\
\hline & ZNF134 & Znf134/Mblr \\
\hline \multicolumn{3}{|c|}{ Undefined function } \\
\hline \multirow[t]{2}{*}{ Asx } & ASXL1 & \\
\hline & ASXL2 & \\
\hline \multicolumn{3}{|l|}{$\mathrm{Crm}$} \\
\hline \multicolumn{3}{|l|}{ Mxc } \\
\hline \multirow[t]{2}{*}{$\mathrm{Scm}$} & SCML1 & Scmh1 \\
\hline & SCML2 & Scmh2 \\
\hline \multirow[t]{2}{*}{$\mathrm{Pcl}$} & hMTF2 & MTF2 \\
\hline & PHF1 & \\
\hline Sxc & & \\
\hline
\end{tabular}


polyhomeotic (Ph), Posterior sex combs (Psc), dRing1 (also known as Sex combs extra, Sce; Fritsch et al. 2003), in addition to Zeste (which has been also classified as a trxG protein), dSbf1, HSC4, and five general transcription factors (dTAFIIs 250, 110, 85, 62, and 42) (Saurin et al. 2001). A second complex, referred to as Esc-E(z), contains the PcG proteins Extra sex combs (Esc), Enhancer of zeste $[\mathrm{E}(\mathrm{z})]$, and Suppressor 12 of zeste [Su(z)12], in addition to the histone-binding protein NURF-55. The histone deacetylase HDAC1 $(\operatorname{Rpd} 3)$ has been identified in some forms of the complex (Tie et al. 2001; Czermin et al. 2002), but is absent from others (Müller et al. 2002). The human counterparts of both complexes have been purified and the core components are found to be conserved (Cao et al. 2002; Levine et al. 2002).

To fully understand the molecular mechanism of PcGmediated gene silencing, several major questions must be addressed. (1) How is the repressed state of target genes initially recognized? (2) What are the mechanisms by which PcG proteins repress transcription? (3) How is the silenced state faithfully transmitted through many cycles of cell division? Here, we describe our recent studies aimed at addressing the latter two questions. In particular, we will discuss the role of sequence-specific DNA-binding $\mathrm{PcG}$ proteins Pleiohomeotic (Pho) and Pho-like (Phol) and H3-K27 methylation by ESC-E(Z)/EED-EZH2 complexes in maintenance of transcriptional silencing. We will also examine the roles of both catalytic and noncatalytic subunits of this HMTase complex and how they contribute to H3-K27 methylation. In addition, we will discuss the mechanisms by which PcG proteins may repress transcription, including the contribution of a novel enzymatic activity associated with the PRC1 complex.

\section{MATERIALS AND METHODS}

All materials used and methods described in the studies presented here have been previously described as indicated throughout the text.

\section{RESULTS}

\section{Purification and Characterization of the EED-EZH2 HMTase Complex}

Histone tails are rich in covalent modifications that include acetylation, methylation, ubiquitination, and phosphorylation (van Holde 1988). While acetylation on lysine residues generally correlates with gene activation, methylation on lysine residues results in either gene activation or repression depending on the particular lysine residues that are methylated (Zhang and Reinberg 2001; Lachner et al. 2003). In an attempt to understand the function of histone methylation, we have been using a systematic biochemical approach to purify and characterize histone methyltransferases from HeLa cells (Fang et al. 2003). Of the six HMTases that we have characterized so far, the EED-EZH2/ESC-E(Z) complex is of particular interest because of its roles in diverse biological processes including PcG silencing, $\mathrm{X}$-inactivation, germ-line development, stem cell pluripotency, and cancer (Cao and Zhang 2004a).

By following a nucleosomal histone H3 methyltransferase activity, we had previously purified a protein complex of about $500 \mathrm{kD}$ from HeLa cells (Cao et al. 2002). The complex is composed of five subunits including EZH2, SUZ12, AEBP2, EED, and RbAp48 (Fig. 1a). A similar protein complex was also purified independently by several other groups (Czermin et al. 2002; Kuzmichev et al. 2002; Müller et al. 2002). RbAp48 is a WD40-repeat protein initially identified as a Rb-binding protein (Qian et al. 1993). Subsequent studies revealed the presence of this protein in many protein complexes involved in histone modification and nucleosome remodeling, consistent with the notion that this protein is a histone-binding protein (Verreault et al. 1998). AEBP2 is a zinc finger transcriptional repressor that may contribute to targeting of the complex to specific genes (He et al. 1999). EZH2, EED, and SUZ12 are PcG proteins (Table 1). Since, with the exception of AEBP2, the composition a

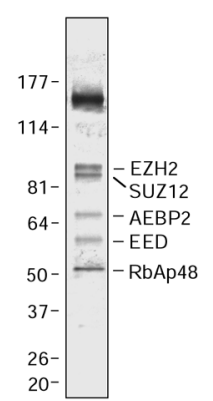

b

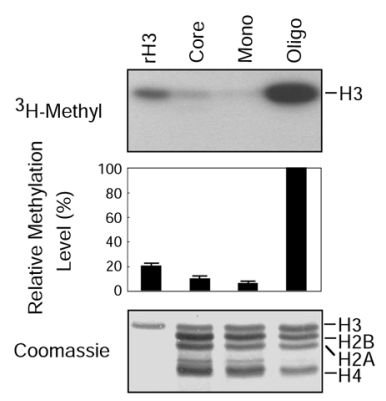

C

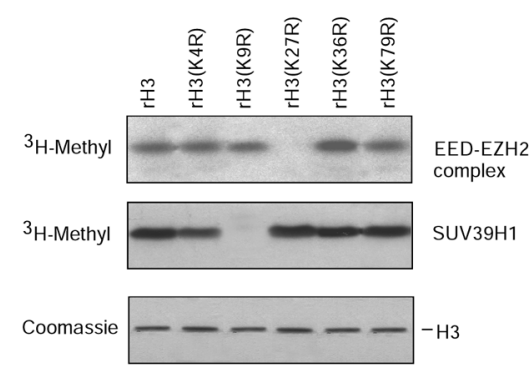

Figure 1. Purification and characterization of the EED-EZH2 histone methyltransferase complex. (a) Coomassie-stained polyacrylamide-SDS gel containing the purified EED-EZH2 complex. The identity of the proteins in the complex is indicated. The largest prominent protein is a contaminant. The protein size markers are indicated. (b) The EED-EZH2 HMTase complex prefers oligonucleosomal histone substrate. Equal amounts of the enzyme complex were used to methylate equal amounts of histone $\mathrm{H} 3$ alone, in octamer, mono-, and oligonucleosome forms (bottom panel). The top panel is an autoradiography of the bottom panel. Quantification of the autoradiography is presented in the middle panel. (c) EED-EZH2 complex methylates $\mathrm{H} 3$ at lysine 27. Equal amounts of wildtype and mutant histone H3 (bottom panel) were methylated by EED-EZH2 complex (top panel) and SUV39H1 (middle panel), respectively. The lysines that were mutated are indicated on top of the panel. (Adapted, with permission, from Cao et al. 2002 [CAAAS].) 
of this complex is conserved in the Drosophila $\mathrm{ESC}-\mathrm{E}(\mathrm{Z})$ complex (Ng et al. 2000; Czermin et al. 2002; Kuzmichev et al. 2002; Müller et al. 2002), we refer to it as the EEDEZH2 complex. The facts that most subunits of the complex belong to the PcG proteins and that EZH2 contains a SET domain suggest a potential link between the intrinsic HMTase activity of the complex and PcG silencing.

To understand the relationship between PcG silencing and the HMTase activity, we characterized the enzymatic activity further by determining its substrate specificity and the lysine residue on $\mathrm{H} 3$ that the complex methylates. Toward this end, equivalent amounts of isolated histone $\mathrm{H} 3$, histone $\mathrm{H} 3$ assembled with other core histones, and mono- or oligonucleosomes were subjected to methylation by equal amounts of the enzyme complex. Results shown in Figure 1b indicate that the enzyme complex has a strong preference for $\mathrm{H} 3$ in oligonucleosome form. To identify the lysine residue that the complex methylates, we generated H3 mutants in which each of the five potential methylation sites (K4, K9, K27, K36, and K79) was individually mutated. The effect of the mutations on the ability of $\mathrm{H} 3$ to serve as substrates for the enzyme complex was evaluated. As a control, the ability of these H3 mutants to serve as substrates for the H3-K9 methyltransferase SUV39H1 was also analyzed. Results shown in Figure 1c (top panel) indicate that mutation on K27 completely abolished the ability of $\mathrm{H} 3$ to serve as a substrate, whereas mutations on other sites had little effect. As expected, only mutation of K9 affected the SUV39H1-mediated H3 methylation (Fig. 1c, middle panel). These results strongly suggest that H3-K27 is the target site of methylation for the complex. To further verify the result, oligonucleosomes were subjected to methylation. After purification, the methylated H3 was subjected to microsequencing followed by liquid scintillation counting. This again revealed that K27 is the target site (Cao et al. 2002). Therefore, we conclude that the EED-EZH2 complex prefers oligonucleosomal substrates and methylates H3-K27.

\section{H3-K27 Methylation Is Required for PRE Binding by $\mathrm{PC}$ and $U b x$ Gene Silencing}

To study the function of H3-K27 methylation in vivo, we generated a polyclonal antibody that recognizes methylated, but not nonmethylated, H3-K27 (Cao et al. 2002). Using this antibody, we evaluated whether the Drosophila ESC-E(Z) complex is responsible for H3K27 methylation in vivo. Previous studies have identified an $E(z)$ temperature-sensitive allele, $E(z)^{61}$, which contains a Cys-to-Tyr substitution (C603Y) in the cysteinerich region immediately preceding the SET domain (Carrington and Jones 1996). At $18^{\circ} \mathrm{C}$ (permissive temperature), the protein functions normally and $E(z)^{61}$ homozygotes exhibit no detectable mutant phenotype and maintain wild-type expression patterns of Hox genes, such as Ubx (Jones and Gelbart 1990; Carrington and Jones 1996). However, at $29^{\circ} \mathrm{C}$ (restrictive temperature), $E(Z) 61$ protein fails to bind to chromatin leading to disruption of chromosome binding by Polycomb (PC) and other PRC1 components (Rastelli et al. 1993; Platero et al. 1996). As a result, $E(z)^{61}$ produces multiple homeotic phenotypes because of derepression of Hox genes (Jones and Gelbart 1990). Therefore, if $E(Z)$ is responsible for H3-K27 methylation in vivo, we expect partial or complete loss of H3-K27 methylation when $E(Z)^{61}$ mutants are shifted from $18^{\circ} \mathrm{C}$ to $29^{\circ} \mathrm{C}$. Results shown in Figure $2 \mathrm{a}$ confirm this prediction and demonstrate that H3-K27 methylation is dramatically decreased in the $E(z)^{61} \mathrm{em}-$ bryos at $29^{\circ} \mathrm{C}$ (middle panel). However, these conditions do not affect $\mathrm{H} 3-\mathrm{K} 9$ methylation (top panel). Therefore, we conclude that functional $\mathrm{E}(\mathrm{Z})$ protein is required for H3-K27 methylation in vivo.

Previous studies have demonstrated that transcriptional silencing of the $U b x$ gene requires both the ESC-E(Z) and the PRC1 complexes, in addition to a cis-acting Polycomb response element (PRE), to which the two complexes bind. To understand the functional relationship between $\mathrm{E}(\mathrm{Z})$-mediated H3-K27 methylation and Hox gene silencing, we analyzed $\mathrm{E}(\mathrm{Z})$ binding, H3-K27 methylation, and recruitment of $\mathrm{PC}$, a core component of the PRC1 complex (Francis et al. 2001), to the major $U b x$ PRE $\left(\mathrm{PRE}_{\mathrm{D}}\right)$ by chromatin immunoprecipitation (ChIP) (Fig. 2b). Analysis of S2 tissue culture cells revealed a precise colocalization of $\mathrm{E}(\mathrm{Z}), \mathrm{H} 3-\mathrm{K} 27$ methylation, and $\mathrm{PC}$ binding to the $\mathrm{PRE}_{\mathrm{D}}$ region (Cao et al. 2002). Importantly, disruption of the ESC-E(Z) complex by RNAi resulted in greatly reduced $\mathrm{E}(\mathrm{Z})$ binding, H3-K27 methylation, and concomitant loss of PC binding to the PRE (Cao et al. 2002), suggesting that ESC-E(Z)-mediated H3-K27 methylation contributes to PRE binding by PC. We also performed similar experiments using dissected wing imaginal discs from homozygous $E(z)^{61}$ larvae, which had been either reared continuously at $18^{\circ} \mathrm{C}$ or shifted from $18^{\circ} \mathrm{C}$ to $29^{\circ} \mathrm{C} \sim 48$ hours prior to dissection. Results shown in Figure 2c (left panels) demonstrate that at permissive temperatures, as in $\mathrm{S} 2$ cells, $\mathrm{E}(\mathrm{Z})^{61}$ binding, $\mathrm{H} 3-$ K27 methylation, and $\mathrm{PC}$ binding colocalize at the $\mathrm{PRE}_{\mathrm{D}}$ region. At restrictive temperatures, however, loss of $\mathrm{E}(\mathrm{Z})^{61}$ binding is concomitant with loss of $\mathrm{H} 3-\mathrm{K} 27$ methylation and PC binding (Fig. 2c, right panels). In contrast, similar changes in $\mathrm{H} 3-\mathrm{K} 9$ methylation were not observed under the same conditions (Fig. 2c). Similar inactivation of an $E(z)$ temperature-sensitive allele during larval development has been shown to result in significant derepression of $U b x$ in wing discs (LaJeunesse and Shearn 1996). Collectively, these data suggest that H3K27 methylation plays an important role in the maintenance of $U b x$ gene silencing.

\section{PC Chromodomain Recognizes Methyl-K27 of H3}

The "histone code" hypothesis predicts that single or combinational histone modifications may serve as molecular marks that can be recognized by specific protein modules or domains that in turn direct the functional consequence of the modification (Strahl and Allis 2000; Turner 2000). Consistent with this hypothesis, the chromodomain of the heterochromatin protein HP1 has been demonstrated to specifically bind to $\mathrm{H} 3$ tails that are methylated at K9 by the HMTase SUV39H1 (Bannister et al. 2001; Lachner et al. 2001). Several lines of evidence 
a

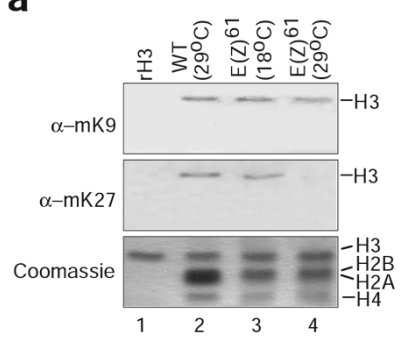

C

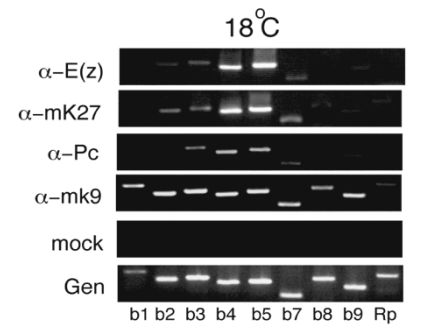

b

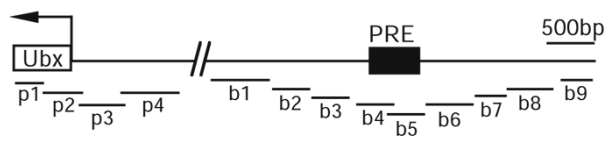

$29^{\circ} \mathrm{C}$

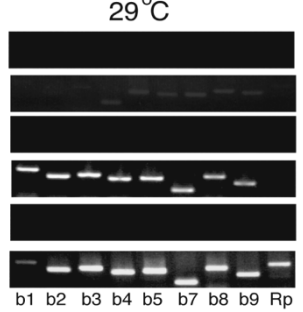

Figure 2. Loss of $\mathrm{E}(\mathrm{Z})$ function abolishes H3-K27 methylation, $\mathrm{PC}$ binding, and Ubx gene silencing. (a) H3-K27 methylation depends on functional $\mathrm{E}(\mathrm{Z})$ protein. Equivalent amounts (bottom panel) of histones purified from wild-type (lane 2$)$ and mutant $\mathrm{E}(\mathrm{z})^{61}$ (lanes 3 and 4) Drosophila embryos were probed with H3-2mK9- (top panel) or H3-2mK27- (middle panel) specific antibodies. (b) Schematic representation of the Ubx promoter and bxd PRE regions. The regions amplified by PCR in these and subsequent ChIP assays, p1-p4 and b1-b9, are depicted as horizontal lines below. (Adapted from Wang et al. 2004.) (c) ChIP assays demonstrate colocalization of $\mathrm{E}(\mathrm{Z})$ binding and $\mathrm{H} 3-\mathrm{K} 27$ methylation in $E(z)^{61}$ wing imaginal discs at $18^{\circ} \mathrm{C}$ (left panel) and loss of binding in wing discs at $29^{\circ} \mathrm{C}$ (right panel). Antibodies used in each assay are indicated on the left. Genomic DNA from pooled collection of wing imaginal discs was PCR amplified as controls for efficiencies of PCR primers. Numbers below the panels indicate the PCR primers used in each ChIP assay. Lanes $1-9$ corresponding to the regions are as indicated in $b$; lane 10 is a PCR product of RpII140 promoter, which served as a negative control. (Adapted, with permission, from Cao et al. 2002 [@AAAS].)

suggest that the chromodomain of $\mathrm{PC}$ may recognize $\mathrm{H} 3$ tails methylated at K27, analogous to that of the HP1 binding to $\mathrm{H} 3$ tails methylated on K9. First, the chromodomain of PC is both necessary and sufficient for targeting PC, as well as other components of the PRC1 complex, to specific chromosomal locations in vivo (Messmer et al. 1992; Platero et al. 1995). Second, loss of $\mathrm{E}(\mathrm{Z})$ function abolishes H3-K27 methylation as well as PC binding to the $U b x$ PRE (Fig. 2c). Third, all the amino acids in HP1 chromodomain that are involved in methyllysine binding are conserved in the PC chromodomain. These lines of evidence prompted us to test the Drosophila PC protein, generated using the rabbit reticulocyte transcription/translation system, for its ability to bind to biotinylated $\mathrm{H} 3$ peptides with or without K27 methylation. Results shown in Figure 3a (top panel) indicated that methylation on $\mathrm{K} 27$ facilitates binding of $\mathrm{PC}$ to the $\mathrm{H} 3$ peptide. This binding is mediated through the chromodomain as mutations in two of the highly conserved amino acids within the chromodomain (W47A, W50A) abolished preferential binding of $\mathrm{PC}$ to the methylated peptide (Fig. 3a, middle panel). Binding of PC to the peptides is specific because the chromodomaincontaining protein HP1 failed to bind to the same peptides under the same conditions (Fig. 3a, bottom panel).

The above in vitro binding results were recently confirmed by structural studies in which the PC chromodomain in complex with an $\mathrm{H} 3$ peptide trimethylated on K27 was crystallized and the structure solved (Fischle et al. 2003; Min et al. 2003). The study revealed a conserved mode of methyl-lysine binding and provided structural basis for specific recognition of $\mathrm{PC}$ chromodomain to histone $\mathrm{H} 3$ methylated on K27, but not K9. As shown in Figure $3 \mathrm{~b}$, the Drosophila PC chromodomain consists of three $\beta$ strands $(\beta 1-\beta 3)$ and a carboxy-terminal helix $(\alpha \mathrm{A})$. The histone $\mathrm{H} 3$ peptide is bound in a cleft formed between the PC amino terminal to $\beta 1$ and the loop connecting $\beta 3$ and $\alpha \mathrm{A}$. Although the overall structures of PC and HP1 chromodomains are very similar (Jacobs and Khorasanizadeh 2002; Nielsen et al. 2002), differences between the two chromodomains are noticeable. For example, while the methyl-lysine-binding pocket of HP1 interacts with methyl-K9 via hydrophobic interaction, the corresponding aromatic residues on PC interact with methyl-K27 through cation $-\pi$ interactions. In addition, unique interactions between Leu 20, Thr 22 of histone $\mathrm{H} 3$, and Arg 67 of PC were noticed. However, these interactions cannot account for the binding specificity of PC chromodomain to methyl-K27, but not methyl-K9, because only the main-chain atoms of histone $\mathrm{H} 3$ are involved in the interaction (Min et al. 2003).

A careful examination of the cocrystal structure identified a potential chromodomain dimer that can account for the binding specificity of PC chromodomain to methylK27. As depicted in Figure 3c, the chromodomain dimer interacts via intermolecular hydrogen bonds between the main-chain atoms of Leu 64 and Arg 66, which appear to be specific to the PC family of proteins. An additional hydrogen bond can also form between Arg 66 and Val 61. The chromodomain dimer juxtaposes the two H3-binding clefts in an antiparallel fashion and results in histone-histone interactions involving Leu 20, Thr 22, and Ala 24 
a

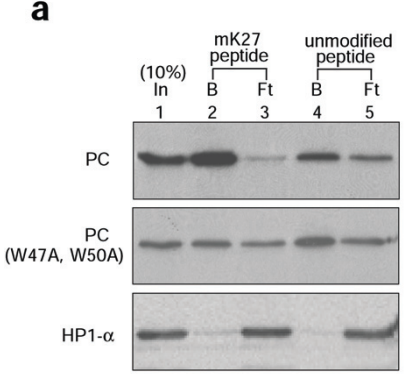

C

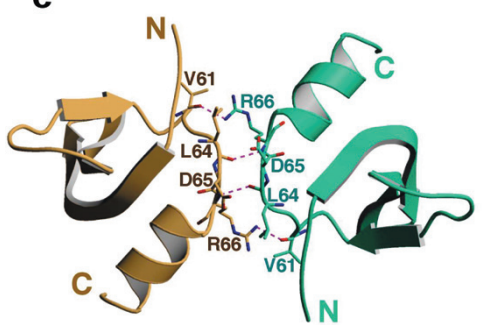

b

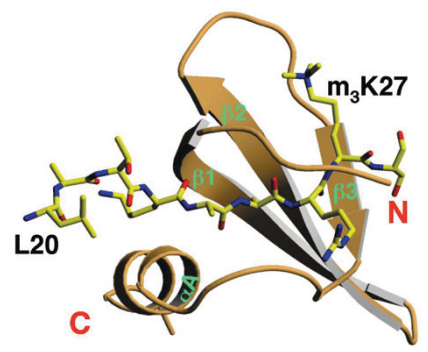

d

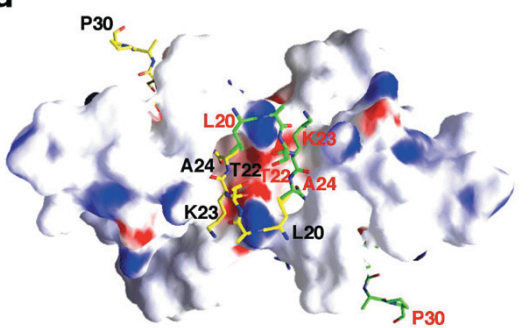

Figure 3. H3-K27 methylation facilitates binding of $\mathrm{PC}$ to $\mathrm{H} 3$ through its chromodomain. (a) Autoradiographs of peptide pulldown experiments. ${ }^{35}$ S-labeled PC, PC mutant (W47A, W50A), and HP1- $\alpha$ were incubated with biotinylated H3 peptides (aa 19-35), which were either methylated or unmethylated at K27, in the presence of streptavidin-conjugated Sepharose beads. After extensive washing, the beads were boiled with SDS loading buffer and resolved in SDS-polyacrylamide gels. In: 10\% of the total input used for the pulldown assays; B: bound; Ft: flowthrough. (b) Overall structure of the Drosophila PC chromodomain (aa 23-77) in complex with a histone $\mathrm{H} 3$ peptide (aa 19-33) trimethylated on K27. The choromodomain is shown in a ribbon diagram (brown), and the H3 peptide is shown as a ball-and-stick model (red, oxygen; blue, nitrogen; and yellow, carbon). (c) The PC chromodomain dimer. The PC chromodomain are shown in a ribbon representation (brown and cyan). Key residues involved in dimerization are shown in a bond model. Hydrogen bonds involving these residues are indicated with broken lines. $(d)$ The PC chromodomain dimer juxtaposes the two binding sites of methyl-K27 of H3. The PC chromodomain dimer is shown as surface representation (red, negatively charged area; blue, positively charged area; white, neutral). Two bound H3-3mK27 peptides are shown in a ball-and-stick model. (Courtesy of Dr. Rui-Ming Xu.)

(Fig. 3d). This recognition mode can effectively exclude the binding of a histone $\mathrm{H} 3$ peptide encompassing methylated Lys 9 , as the residues corresponding to Leu 20, Thr 22, and Ala 24 of H3 would be Arg 2, Lys 4, and Thr 5 , respectively. Therefore, the key determinants that confer specific recognition of methyl-K27 by PC chromodomain are both the histone H3 sequence (Leu 20, Thr 22, and Ala 24) and the dimerization of the PC chromodomain.

\section{H3-K27 Methylation Contributes to PC/PRC1 Recruitment}

As described above, loss of $\mathrm{E}(\mathrm{Z})$ results in rapid loss of H3-K27 methylation and PC binding to the $\mathrm{PRE}_{\mathrm{D}}$ region. Previous studies also suggest that the E(Z) complex can transiently interact with components of the PRC1 complex (Poux et al. 2001). Therefore, results from the above study cannot distinguish between the contribution of H3K27 methylation and the physical interaction between the ESC-E(Z) complex and the PRC1 components in PC recruitment. However, ChIP analysis indicate that $\mathrm{E}(\mathrm{Z})$, $\mathrm{PC}$, and trimethyl H3-K27 are also present near the $U b x$ promoter in wing imaginal discs (Fig. 4a). Following inactivation of $\mathrm{E}(\mathrm{Z})^{61}$ and loss of the HMTase complex, H3-K27 methylation is maintained near the Ubx promoter for $\sim 24$ hours. PC also remains near the Ubx pro- moter in the absence of $\mathrm{E}(\mathrm{Z})$, but is finally lost when $\mathrm{H} 3$ K27 methylation is no longer detectable (Fig. 4b). Thus, PC binding correlates with H3-K27 methylation, but not with the physical presence of $\mathrm{E}(\mathrm{Z})$-containing complex, consistent with $\mathrm{H} 3-\mathrm{K} 27$ methylation serving as a tag that is primarily responsible for recruiting PC-containing complexes. a

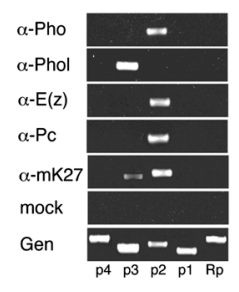

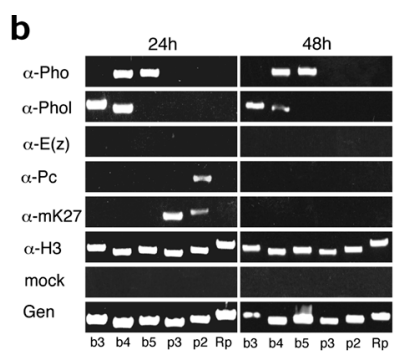

b
Figure 4. $P c$ binding at the $U b x$ promoter and $P R E_{D}$ regions is dependent on H3-K27 methylation. (a) ChIP assays showing distribution of PcG proteins and $\mathrm{H} 3-3 \mathrm{mK} 27$ in the Ubx promoter region in wing imaginal discs. Wing imaginal discs were dissected from $E(z)^{61}$ larvae reared continuously at $18^{\circ} \mathrm{C}$. (b) ChIP assays of wing imaginal discs from $E(z)^{61}$ larvae shifted from $18^{\circ} \mathrm{C}$ to $29^{\circ} \mathrm{C}$ (left) $24 \mathrm{hr}$ or (right) $48 \mathrm{hr}$ prior to dissection. $\alpha-\mathrm{H} 3$, anti-histone $\mathrm{H} 3$ was used as a positive control in the ChIP assays shown in this figure and in Fig. 5. (Adapted, with permission, from Wang et al. 2004 [@Elsevier].) 


\section{Hierarchical Recruitment of PcG Complexes}

PcG proteins maintain the transcriptionally silenced state of target genes through many cell cycles. Both initiation and maintenance of transcriptional silence require a cis-acting PRE. Reporter genes contained within P element constructs become derepressed after one to a few cell generations following deletion of a flanking PRE (Busturia et al. 1997; Sengupta et al. 2004). Several components of the PRC1 dissociate from chromosomes in tissue culture cells during mitosis (Buchenau et al. 1998). This suggests that proteins capable of binding directly to sites within PREs play important roles in repeatedly recruiting PcG proteins to PREs following mitosis. PREs contain binding sites for several sequence-specific DNAbinding proteins. These include GAGA factor, Pipsqueak (Psq), Pleiohomeotic (Pho), and Pho-like (Phol). GAGA factor and Psq both bind to GAGAG repeats and mutation of these sequences in $\mathrm{PRE}_{\mathrm{D}}$ within the context of a P element transgene results in partial derepression of a reporter gene in embryos (Horard et al. 2000; Hodgson et al. 2001). However, GAGA factor and Psq may not be required for maintenance of $\mathrm{PcG}$ silencing in larvae, since mutation of PRE GAGAG sites does not affect repression of a reporter gene in imaginal discs (Fritsch et al. 1999).

Pho and Phol are homologs of human Yin Yang 1 (YY1), and are identical in their sequence-specific DNAbinding activities in vitro (Brown et al. 1998, 2003). Maternally expressed Pho is needed early in embryogenesis in order to establish PcG silencing, but individuals that are homozygous for null pho alleles (derived from heterozygous mothers) die as late pupae with relatively mild homeotic phenotypes and show only moderate derepression of Ubx in wing imaginal discs (Brown et al. 2003). The relatively mild zygotic phenotypes of pho mutants

a

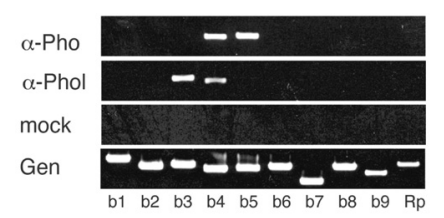

b

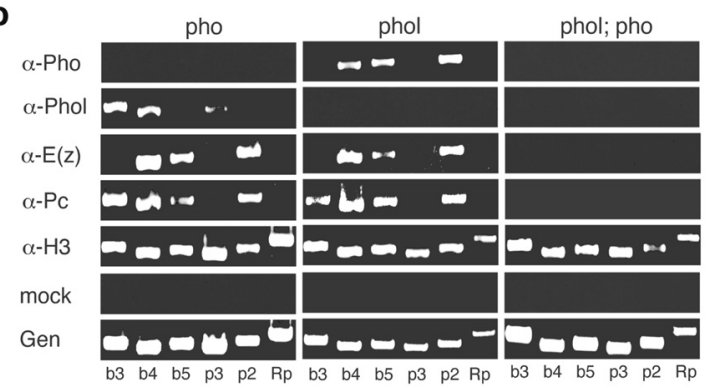

Figure 5. Pho and Phol are redundant for recruitment of E(z)and Pc-containing complexes. (a) ChIP assays showing distribution of Pho and Phol in the $\mathrm{PRE}_{\mathrm{D}}$ region in wing imaginal discs. (b) ChIP assays of wing imaginal discs dissected from pho ${ }^{I}$ (left), phol ${ }^{81 A}$ (middle), or pho phol $^{81 A}$ (right) larvae. (Adapted, with permission, from Wang et al. 2004 [@Elsevier].) appear to be due to functional redundancy with phol. Although phol nulls are homozygous viable, phol;pho double mutants exhibit extensive $U b x$ derepression in wing imaginal discs and die as late larvae/early pupae (Brown et al. 2003). This suggests that Pho and Phol play important roles in maintaining PcG silencing during larval development and that their functions may be partially redundant. We have recently demonstrated that $\mathrm{PHO}$ and PHOL directly interact with $\mathrm{E}(\mathrm{Z})$ and/or ESC (Wang et al. 2004), which suggests that the ESC-E(Z) complex may be recruited to PREs through protein-protein interactions with PHO and/or PHOL. ChIP analysis of wing imaginal discs revealed the presence of PHO and PHOL in the $\mathrm{PRE}_{\mathrm{D}}$ and $U b x$ promoter regions at sites that overlapped those of $\mathrm{E}(\mathrm{Z})$ and $\mathrm{PC}$ (Figs. 4a, 5a). Binding by neither $\mathrm{E}(\mathrm{Z})$ nor $\mathrm{PC}$ was affected in phol or pho mutant wing imaginal discs. However, binding by both $\mathrm{E}(\mathrm{Z})$ and PC is lost in phol; pho double mutants (Fig. 5b). Taken together with the role of $\mathrm{H} 3-\mathrm{K} 27$ methylation in $\mathrm{PC}$ recruitment described above, we propose the following hierarchical pathway of $\mathrm{PcG}$ recruitment. $\mathrm{PHO}$ and/or PHOL bind to sites within PREs and directly recruit ESC$\mathrm{E}(\mathrm{Z})$ complex, which then methylates $\mathrm{H} 3$ at K27. The PC chromodomain then binds to the methylated H3-K27 tag, facilitating recruitment of $\mathrm{PC}$-containing complexes such as PRC1 (Fig. 6).

In addition to their presence at the $\mathrm{PRE}_{\mathrm{D}}$ region, $\mathrm{Pc}$, $\mathrm{E}(\mathrm{z})$, Pho, and Phol are associated with discrete regions near the transcription start site (Fig. 4a). In the absence of
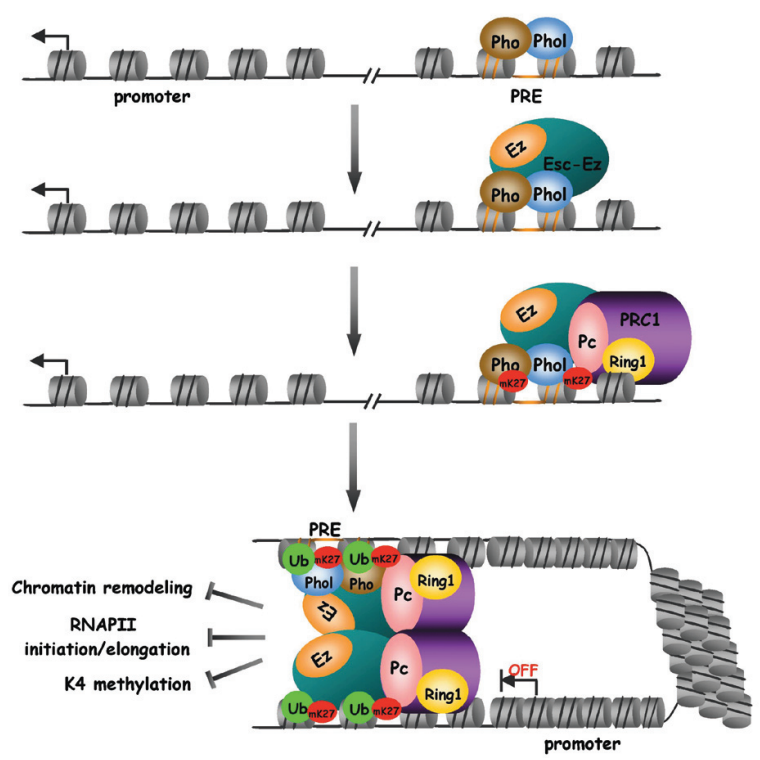

Figure 6. Model depicting the mechanism of PcG silencing. Binding of transcription factors, such as Pho and Phol, to PRE initiates the recruitment of the $\operatorname{ESC}-\mathrm{E}(\mathrm{Z})$ complex, which methylates H3-K27. H3-3mK27, recognized by the chromodomain of PC, serves as a marker for the recruitment of the PRC1 complex. A yet-to-be-identified mechanism mediates loop formation bringing the PRE and associated PcG proteins into proximity of the transcriptional start site, which inhibits transcription by (1) interfering with chromatin remodeling, (2) directly inhibiting transcription initiation or elongation by RNAPII, and/or (3) ubiquitinating histone $\mathrm{H} 2 \mathrm{~A}$, thereby inhibiting H3-K4 methylation by Trx and/or Ash1 complexes. 
E(z), Pho and Phol remain at the PRE, but are no longer detected near the $U b x$ promoter (Fig. 4b). This is consistent with a model in which PcG proteins assemble at the PRE followed by the formation of a loop that brings them into contact with the promoter (Fig. 6). Assuming this model is correct, it is not clear what may mediate loop formation. PRC1 has been shown to be able to recruit chromatin templates in trans (Lavigne et al. 2004). Alternatively, the sequence-specific DNA-binding protein Zeste has been shown to be a component of PRC1 (Saurin et al. 2001), raising the possibility that Zeste may mediate loop formation.

\section{Evolutionary Conservation of PcG Gene Silencing}

As listed in Table 1, PcG proteins have been structurally and functionally conserved during evolution. In addition, the core components of the ESC-E(Z)/EEDEZH2 and the PRC1 complexes are conserved from Drosophila to human (Francis et al. 2001; Cao et al. 2002; Levine et al. 2002; Muller et al. 2002). One of the conserved functions of PcG proteins is their involvement in Hox gene silencing. For example, PcG mutations in Drosophila or mice result in homeotic transformation because of derepression of Hox genes (Kmita and Duboule 2003). Data presented above illustrate the importance of ESC-E(Z)-mediated H3-K27 methylation in $U b x$ gene silencing. To examine whether the function of H3-K27 methylation is conserved in mammalian cells, we reconstituted the human EED-EZH2 complex and demonstrated that the HMTase activity requires a minimum of three components, including EZH2, EED, and SUZ12. Addition of RbAp48 and AEBP2 stimulated the enzymatic activity (Cao and Zhang 2004b).

To evaluate the role of SUZ12 in H3-K27 methylation in vivo, we generated a stable SUZ12 knockdown cell line that expresses $\sim 25 \%$ of the normal levels of SUZ12 protein and $\sim 35 \%$ of the normal levels of SUZ12 mRNA (Fig. 7a). Compared with the control empty vector knockdown cells, SUZ12-targeted knockdown resulted in a sig- nificant decrease on the trimethyl-K27 level but had little effect on the trimethyl-K9 level (Fig. 7b, third and fourth panels). Interestingly, an increase in monomethyl-K27 and a moderate decrease in dimethyl-K27 were also observed (Fig. 7b, top two panels). The fact that SUZ12 knockdown does not affect EZH2 level (Fig. 7a) in combination with the requirement of SUZ12 for H3-K27 methyltransferase activity in vitro (Fig. 7b) allows us to conclude that SUZ12 directly contributes to H3-K27 methylation in vivo.

Previous studies in Drosophila have established a critical role for $\mathrm{Su}(\mathrm{z}) 12$ in Hox gene silencing (Birve et al. 2001). The fact that SUZ12 is required for H3-K27 methylation in combination with the fact that H3-K27 methylation is critical in Hox gene silencing (Cao et al. 2002; Muller et al. 2002) predict that SUZ12 knockdown will result in derepression of at least some Hox genes. Analysis of HoxC6, HoxC8, and HoxA9 in the knockdown cells and the parallel control cells revealed derepression of HoxC8 and HoxA9 genes in the knockdown cells (Fig. 7c). These data support the notion that, like most other PcG proteins, the function of SUZ12/Su(z)12 in Hox gene silencing is conserved from human to Drosophila.

\section{CONCLUSIONS AND FUTURE DIRECTIONS}

As a result of these and other studies, we can now begin to assign molecular/biochemical activities to more than half of the known PcG proteins. We propose that PcG proteins may be placed in either of two categories: Recruiters or Effectors. Proteins such as Pho, Phol, or their mammalian homolog YY1 and components of the Esc-E(z)/EED-EZH2 complex primarily function as Recruiters. The sequence-specific DNA-binding Pho and Phol bind to sites within PREs and directly recruit ESC$\mathrm{E}(\mathrm{Z})$ complexes, which in turn methylates $\mathrm{H} 3$ at $\mathrm{K} 27$ in the immediate vicinity of the PRE. The PC chromodomain binds to the methylated H3-K27 tag, facilitating recruitment of PRC1, or related complexes (Fig. 6). Thus,
Figure 7. SUZ12 knockdown affects H3-K27 methylation and Hox gene expression. (a) Western blot (left panel) and quantitative RT-PCR (right panel) analysis of a SUZ12 stable knockdown cell line and a parallel mock knockdown cell line. Tubulin serves as a loading control for Western blotting. GAPDH serves as control for normalization in the quantitative RT-PCR. (b) Western blot analysis of histones extracted from control and knockdown HeLa cells with antibodies specific for mono-, di-, or trimethylated K27 and trimethylated K9. Equal loading of histone $\mathrm{H} 3$ was verified by Coomassie staining of a parallel gel (bottom panel). (c) Quantitative RTPCR analysis of HoxC6, HoxC8, and HoxA9 expression in SUZ12 knockdown and mock knockdown cells. GAPDH was used as a control for normalization. Quantification is an average of two independent experiments with error bars. (Adapted from Cao and Zhang 2004b.) a
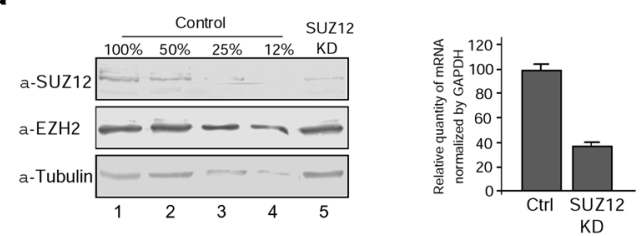

b

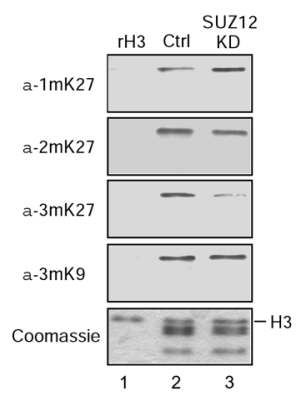

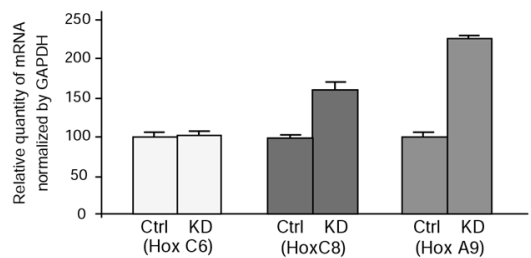


the primary function of H3-K27 methylation in PcG silencing appears to be recruitment of PC-containing complexes. In vitro studies suggest that PRC1 may be classified as an Effector of transcriptional repression, which may inhibit transcription by any of several possible mechanisms. For example, PRC1 inhibits nucleosome remodeling by SWI/SNF complexes (Shao et al. 1999; Francis et al. 2001). Therefore, it may antagonize the nucleosome remodeling activity of the trxG BRM complex, thus interfering with activator binding or assembly of the preinitiation complex. In addition, PRC1 has been shown to be able to block transcription of chromatin or naked DNA templates by RNA polymerase II or T7 RNA polymerase (King et al. 2002). PRC1 does not appear to block activator binding in these assays, but instead seems to act upon the template to interfere with transcription initiation or elongation. These observations are consistent with in vivo studies in which RNA polymerase II and basal transcription factors were shown to be present at promoters under conditions of PcG repression (Dellino et al. 2004) and the presence of $\mathrm{Pc}$ - and $\mathrm{E}(\mathrm{z})$-containing complexes at a discrete site just downstream of a silenced endogenous target gene, $U b x$, in wing imaginal discs (Wang et al. 2004). In addition, our recent studies indicate that a PRC1-like complex possesses H2A ubiquitin ligase activity. Human Ring 2, a homolog of dRing/Sce, was identified as the catalytic subunit (data not shown). Although the mechanism by which this activity affects transcription has not been determined, it nevertheless suggests that PRC1 may interfere with transcription by multiple mechanisms.

Among the questions to be addressed in the near future is whether PRE-promoter loops actually form, what is the mechanistic basis for loop formation, and how are PcG complexes targeted to a site just downstream of the transcription start site. Once positioned downstream of the transcription start site, what is the mechanism by which transcription is prevented? Does PRC1 directly act upon the DNA template to prevent duplex melting, or might it interfere with some step in initiation such as RNA polymerase II CTD phosphorylation? What is the effect of $\mathrm{H} 2 \mathrm{~A}$ ubiquitination by dRing/hRing2? It is also important to point out that of the 15 genetically identified $\mathrm{PcG}$ genes, the products of only 9 have been identified either as sequence-specific DNA-binding proteins (Pho and Phol) or components of the PRC1 (Pc, Ph, Psc, dRing) or Esc-E(z) (Esc, E(z), Su(z)12) complexes. The remaining PcG proteins also play important roles in transcriptional silencing, but their activities are yet to be defined. In addition, other proteins, which may have pleiotropic functions and therefore are not easily classifiable as members of the PcG on the basis of genetic studies, also contribute to PcG silencing. Full understanding of this epigenetic gene regulation system will require an understanding of these other players in addition to those that have received the bulk of our attention to date.

\section{ACKNOWLEDGMENTS}

This work was supported by NIH grants GM068804 (Y.Z.) and GM46567 (R.S.J.).

\section{REFERENCES}

Bannister A.J., Zegerman P., Partridge J.F., Miska E.A., Thomas J.O., Allshire R.C., and Kouzarides T. 2001. Selective recognition of methylated lysine 9 on histone H3 by the HP1 chromo domain. Nature 410: 120.

Beisel C., Imhof A., Greene J., Kremmer E., and Sauer F. 2002. Histone methylation by the Drosophila epigenetic transcriptional regulator Ash1. Nature 419: 857.

Bernstein B.E., Humphrey E.L., Erlich R.L., Schneider R., Bouman P., Liu J.S., Kouzarides T., and Schreiber S.L. 2002. Methylation of histone H3 Lys 4 in coding regions of active genes. Proc. Natl. Acad. Sci. 99: 8695 .

Birve A., Sengupta A.K., Beuchle D., Larsson J., Kennison J.A., Rasmuson-Lestander A., and Muller J. 2001. Su(z)12, a novel Drosophila Polycomb group gene that is conserved in vertebrates and plants. Development 128: 3371.

Brown J.L., Fritsch C., Mueller J., and Kassis J.A. 2003. The Drosophila pho-like gene encodes a YY1-related DNA binding protein that is redundant with pleiohomeotic in homeotic gene silencing. Development 130: 285.

Brown J.L., Mucci D., Whiteley M., Dirksen M.L., and Kassis J.A. 1998. The Drosophila Polycomb group gene pleiohomeotic encodes a DNA binding protein with homology to the transcription factor YY1. Mol. Cell 1: 1057.

Buchenau P., Hodgson J., Strutt H., and Arndt-Jovin D.J. 1998. The distribution of polycomb-group proteins during cell division and development in Drosophila embryos: Impact on models for silencing. J. Cell Biol. 141: 469.

Busturia A., Wightman C.D., and Sakonju S. 1997. A silencer is required for maintenance of transcriptional repression throughout Drosophila development. Development 124: 4343.

Byrd K.N. and Shearn A. 2003. ASH1, a Drosophila trithorax group protein, is required for methylation of lysine 4 residues on histone H3. Proc. Natl. Acad. Sci. 100: 11535.

Cao R. and Zhang Y. 2004a. The functions of E(Z)/EZH2-mediated methylation of lysine 27 in histone H3. Curr. Opin. Genet. Dev. 14: 155.

- 2004b. SUZ12 is required for both the histone methyltransferase activity and the silencing function of the EEDEZH2 complex. Mol. Cell 15: 57.

Cao R., Wang L., Wang H., Xia L., Erdjument-Bromage H., Tempst P., Jones R.S., and Zhang Y. 2002. Role of histone H3 lysine 27 methylation in Polycomb-group silencing. Science 298: 1039 .

Carrington E.A. and Jones R.S. 1996. The Drosophila Enhancer of zeste gene encodes a chromosomal protein: Examination of wild-type and mutant protein distribution. Development 122: 4073.

Czermin B., Melfi R., McCabe D., Seitz V., Imhof A., and Pirrotta V. 2002. Drosophila Enhancer of Zeste/ESC complexes have a histone $\mathrm{H} 3$ methyltransferase activity that marks chromosomal Polycomb sites. Cell 111: 185.

Daubresse G., Deuring R., Moore L., Papoulas O., Zakrajsek I., Waldrip W.R., Scott M.P., Kennison J.A., and Tamkun J.W. 1999. The Drosophila kismet gene is related to chromatin-remodeling factors and is required for both segmentation and segment identity. Development 126: 1175

Dellino G.I., Schwartz Y.B., Farkas G., McCabe D., Elgin S.C., and Pirrotta V. 2004. Polycomb silencing blocks transcription initiation. Mol. Cell 13: 887.

Fang J., Wang H., and Zhang Y. 2003. Purification of histone methyltransferases from HeLa cells. Methods Enzymol. 377: 213.

Fischle W., Wang Y., Jacobs S.A., Kim Y., Allis C.D., and Khorasanizadeh S. 2003. Molecular basis for the discrimination of repressive methyl-lysine marks in histone $\mathrm{H} 3$ by Polycomb and HP1 chromodomains. Genes Dev. 17: 1870.

Francis N.J. and Kingston R.E. 2001. Mechanisms of transcriptional memory. Nat. Rev. Mol. Cell Biol. 2: 409.

Francis N.J., Saurin A.J., Shao Z., and Kingston R.E. 2001. Reconstitution of a functional core polycomb repressive complex. Mol. Cell 8: 545 .

Fritsch C., Beuchle D., and Muller J. 2003. Molecular and ge- 
netic analysis of the Polycomb group gene Sex combs extra/Ring in Drosophila. Mech. Dev. 120: 949.

Fritsch C., Brown J.L., Kassis J.A., and Muller J. 1999. The DNA-binding polycomb group protein pleiohomeotic mediates silencing of a Drosophila homeotic gene. Development 126: 3905 .

He G.P., Kim S., and Ro H.S. 1999. Cloning and characterization of a novel zinc finger transcriptional repressor. A direct role of the zinc finger motif in repression. J. Biol. Chem. 274: 14678.

Hodgson J.W., Argiropoulos B., and Brock H.W. 2001. Sitespecific recognition of a 70-base-pair element containing $\mathrm{d}(\mathrm{GA})(\mathrm{n})$ repeats mediates bithoraxoid polycomb group response element-dependent silencing. Mol. Cell. Biol. 21: 4528 .

Horard B., Tatout C., Poux S., and Pirrotta V. 2000. Structure of a polycomb response element and in vitro binding of polycomb group complexes containing GAGA factor. Mol. Cell. Biol. 20: 3187.

Jacobs S.A. and Khorasanizadeh S. 2002. Structure of HP1 chromodomain bound to a lysine 9-methylated histone $\mathrm{H} 3$ tail. Science 295: 2080.

Jenuwein T., Laible G., Dorn R., and Reuter G. 1998. SET domain proteins modulate chromatin domains in eu- and heterochromatin. Cell. Mol. Life Sci. 54: 80.

Jones R.S. and Gelbart W.M. 1990. Genetic analysis of the enhancer of zeste locus and its role in gene regulation in Drosophila melanogaster. Genetics 126: 185.

Kal A.J., Mahmoudi T., Zak N.B., and Verrijzer C.P. 2000. The Drosophila brahma complex is an essential coactivator for the trithorax group protein zeste. Genes Dev. 14: 1058.

King I.F., Francis N.J., and Kingston R.E. 2002. Native and recombinant polycomb group complexes establish a selective block to template accessibility to repress transcription in vitro. Mol. Cell. Biol. 22: 7919.

Kmita M. and Duboule D. 2003. Organizing axes in time and space; 25 years of colinear tinkering. Science 301: 331.

Kuzmichev A., Nishioka K., Erdjument-Bromage H., Tempst P., and Reinberg D. 2002. Histone methyltransferase activity associated with a human multiprotein complex containing the Enhancer of Zeste protein. Genes Dev. 16: 2893.

Lachner M., O'Sullivan R.J., and Jenuwein T. 2003. An epigenetic road map for histone lysine methylation. J. Cell Sci. 116: 2117.

Lachner M., O'Carroll D., Rea S., Mechtler K., and Jenuwein T. 2001. Methylation of histone H3 lysine 9 creates a binding site for HP1 proteins. Nature 410: 116.

LaJeunesse D. and Shearn A. 1996. E(z): A polycomb group gene or a trithorax group gene? Development 122: 2189.

Lavigne M., Francis N.J., King I.F., and Kingston R.E. 2004. Propagation of silencing; recruitment and repression of naive chromatin in trans by polycomb repressed chromatin. Mol. Cell 13: 415.

Levine S.S., Weiss A., Erdjument-Bromage H., Shao Z., Tempst P., and Kingston R.E. 2002. The core of the polycomb repressive complex is compositionally and functionally conserved in flies and humans. Mol. Cell. Biol. 22: 6070.

Messmer S., Franke A., and Paro R. 1992. Analysis of the functional role of the Polycomb chromo domain in Drosophila melanogaster. Genes Dev. 6: 1241.

Min J., Zhang Y., and Xu R.M. 2003. Structural basis for specific binding of Polycomb chromodomain to histone H3 methylated at Lys 27. Genes Dev. 17: 1823.

Müller J., Hart C.M., Francis N.J., Vargas M.L., Sengupta A., Wild B., Miller E.L., O'Connor M.B., Kingston R.E., and Simon J.A. 2002. Histone methyltransferase activity of a Drosophila Polycomb group repressor complex. Cell 111: 197.

Ng J., Hart C.M., Morgan K., and Simon J.A. 2000. A Drosophila $\mathrm{ESC}-\mathrm{E}(\mathrm{Z})$ protein complex is distinct from other polycomb group complexes and contains covalently modified ESC. Mol. Cell. Biol. 20: 3069.

Nielsen P.R., Nietlispach D., Mott H.R., Callaghan J., Bannister
A., Kouzarides T., Murzin A.G., Murzina N.V., and Laue E.D. 2002. Structure of the HP1 chromodomain bound to histone $\mathrm{H} 3$ methylated at lysine 9. Nature 416: 103.

Papoulas O., Beek S.J., Moseley S.L., McCallum C.M., Sarte M., Shearn A., and Tamkun J.W. 1998. The Drosophila trithorax group proteins BRM, ASH1 and ASH2 are subunits of distinct protein complexes. Development 125: 3955.

Petruk S., Sedkov Y., Smith S., Tillib S., Kraevski V., Nakamura T., Canaani E., Croce C.M., and Mazo A. 2001. Trithorax and dCBP acting in a complex to maintain expression of a homeotic gene. Science 294: 1331.

Platero J.S., Hartnett T., and Eissenberg J.C. 1995. Functional analysis of the chromo domain of HP1. EMBO J. 14: 3977.

Platero J.S., Sharp E.J., Adler P.N., and Eissenberg J.C. 1996. In vivo assay for protein-protein interactions using Drosophila chromosomes. Chromosoma 104: 393.

Poux S., Melfi R., and Pirrotta V. 2001. Establishment of Polycomb silencing requires a transient interaction between PC and ESC. Genes Dev. 15: 2509.

Qian Y.-W., Wang Y.-C.J., Hollingsworth R.E.J., Jones D., Ling N., and Lee E.Y.-H.P. 1993. A retinoblastoma-binding protein related to a negative regulator of Ras in yeast. Nature 364: 648 .

Rastelli L., Chan C.S., and Pirrotta V. 1993. Related chromosome binding sites for zeste, suppressors of zeste and Polycomb group proteins in Drosophila and their dependence on Enhancer of zeste function. EMBO J. 12: 1513.

Rea S., Eisenhaber F., O'Carroll D., Strahl B.D., Sun Z.W., Schmid M., Opravil S., Mechtler K., Ponting C.P., Allis C.D., and Jenuwein T. 2000. Regulation of chromatin structure by site-specific histone H3 methyltransferases. Nature 406: 593.

Ruhf M.L., Braun A., Papoulas O., Tamkun J.W., Randsholt N., and Meister M. 2001. The domino gene of Drosophila encodes novel members of the SWI2/SNF2 family of DNA-dependent ATPases, which contribute to the silencing of homeotic genes. Development 128: 1429.

Saurin A.J., Shao Z., Erdjument-Bromage H., Tempst P., and Kingston R.E. 2001. A Drosophila Polycomb group complex includes Zeste and dTAFII proteins. Nature 412: 655.

Sengupta A.K., Kuhrs A., and Muller J. 2004. General transcriptional silencing by a Polycomb response element in Drosophila. Development 131: 1959.

Shao Z., Raible F., Mollaaghababa R., Guyon J.R., Wu C.T., Bender W., and Kingston R.E. 1999. Stabilization of chromatin structure by PRC1, a Polycomb complex. Cell 98: 37.

Simon J.A. and Tamkun J.W. 2002. Programming off and on states in chromatin: Mechanisms of Polycomb and trithorax group complexes. Curr. Opin. Genet. Dev. 12: 210.

Smith S.T., Petruk S., Sedkov Y., Cho E., Tillib S., Canaani E., and Mazo A. 2004. Modulation of heat shock gene expression by the TAC 1 chromatin-modifying complex. Nat. Cell Biol. 6: 162 .

Strahl B.D. and Allis C.D. 2000. The language of covalent histone modifications. Nature 403: 41.

Tie F., Furuyama T., Prasad-Sinha J., Jane E., and Harte P.J. 2001. The Drosophila Polycomb Group proteins ESC and $\mathrm{E}(\mathrm{Z})$ are present in a complex containing the histone-binding protein $\mathrm{p} 55$ and the histone deacetylase RPD3. Development 128: 275 .

Turner B.M. 2000. Histone acetylation and an epigenetic code. Bioessays 22: 836.

van Holde K.E. 1988. Histone modifications. Springer, New York.

Verreault A., Kaufman P.D., Kobayashi R., and Stillman B. 1998. Nucleosomal DNA regulates the core-histone-binding subunit of the human Hat1 acetyltransferase. Curr. Biol. 8: 96.

Wang L., Brown J.L., Cao R., Zhang Y., Kassis J.A., and Jones R.S. 2004. Hierarchical recruitment of polycomb group silencing complexes. Mol. Cell 14: 637.

Zhang Y. and Reinberg D. 2001. Transcription regulation by histone methylation: Interplay between different covalent modifications of the core histone tails. Genes Dev. 15: 2343. 


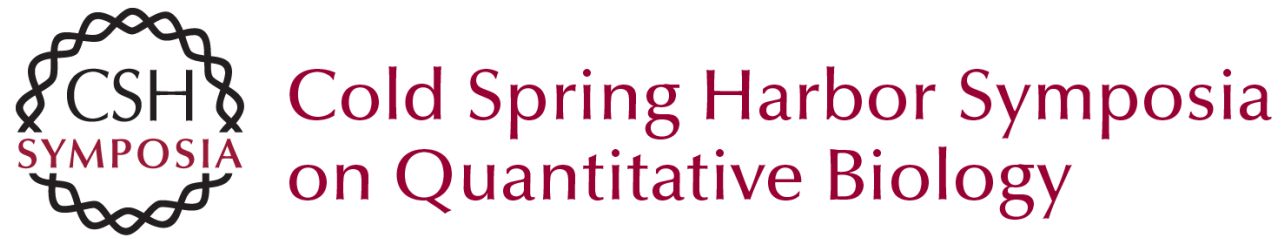

\section{Mechanism of Polycomb Group Gene Silencing}

Y. ZHANG, R. CAO, L. WANG, et al.

Cold Spring Harb Symp Quant Biol 2004 69: 309-318

Access the most recent version at doi:10.1101/sqb.2004.69.309

References This article cites 62 articles, 33 of which can be accessed free at: http://symposium.cshlp.org/content/69/309.full.html\#ref-list-1

\section{License}

Email Alerting Receive free email alerts when new articles cite this article - sign up in Service the box at the top right corner of the article or click here. 